\title{
Danos Visuais e anatômicos Causados pelo Glyphosate em FOLHAS DE Eucalyptus grandis
}

\author{
Visible and Anatomic Damages Caused by Glyphosate in Eucalyptus grandis Leaves
}

\author{
TUFFI SANTOS, L.D. ${ }^{2}$, SANT’ANNA-SANTOS, B.F. ${ }^{3}$, MEIRA, R.M.S.A. ${ }^{4}$, TIBURCIO, R.A.S. ${ }^{5}$, \\ FERREIRA, F.A. ${ }^{6}$, MELO, C.A.D. ${ }^{7}$ e SILVA, E.F.S. ${ }^{7}$
}

\begin{abstract}
RESUMO - A sintomatologia é um dos principais critérios adotados para avaliar os danos causados por fatores bióticos e abióticos em plantas. Contudo, aspectos microscópicos são necessários na compreensão dos mecanismos de intoxicação e no diagnóstico precoce da injúria. Objetivou-se no presente estudo avaliar os efeitos da deriva simulada de quatro formulações comerciais de glyphosate (Scout ${ }^{\circledR}$, Roundup NA ${ }^{\circledR}$, Roundup transorb ${ }^{\circledR}$ e Zapp QI ${ }^{\circledR}$ ) sobre a morfoanatomia foliar de seis clones de Eucalyptus grandis (UFV01, UFV02, UFV03, UFV04, UFV05 e UFV06). Após a aplicação do glyphosate na dose de 129,6 g ha-1, acompanhouse diariamente o surgimento de sintomas, e aos 14 dias coletaram-se amostras de folhas aparentemente sadias para as análises microscópicas. Todos os clones apresentaram cloroses e necroses a partir do quarto dia de exposição, independentemente da formulação utilizada. O clone UFVO4 não apresentou injúrias anatômicas. Nos demais clones, os herbicidas ocasionaram plasmólise, colapso celular, hipertrofia e formação de tecido de cicatrização, porém não foram diagnosticadas variações na espessura das folhas. Visualmente, o Roundup transorb ${ }^{\circledR}$ foi o herbicida que provocou maior intoxicação nas plantas. Anatomicamente, plantas expostas ao Roundup $\mathrm{NA}^{\circledR}$ apresentaram maior número de danos. O clone UFV06 foi o mais sensivel à ação das formulações testadas, considerandose tanto a análise visual quanto a anatômica. Os resultados confirmam o valor diagnóstico da análise visual e prognóstico da anatomia vegetal, sendo o estudo conjunto desses parâmetros fundamental para avaliar a sensibilidade entre os clones e o potencial fitotóxico de herbicidas.
\end{abstract}

Palavras-chave: anatomia vegetal, herbicida, sintomatologia.

\begin{abstract}
Symptomatology is one of the most important criteria used to determine the damages caused by biotic and abiotic factors in plants. However, microscopic aspects are needed to elucidate intoxication mechanisms and early injury diagnosis. This work aimed to evaluate the effects of four commercial glyphosate formulations under simulated spray drift (Scout ${ }^{\mathbb{}}$, Roundup $N A^{\circledR}$, Roundup transorb $^{\circledR}$ and Zapp QI ${ }^{\mathbb{}}$ ) on the morphoanatomy of six Eucalyptus grandis clones (UFVO1, UFVO2, UFVO3, UFVO4, UFVO5 and UFVO6). Following glyphosate application (129.6 $\mathrm{g} \mathrm{ha}^{-1}$ ), symptoms were monitored daily and, at 14 days, leaf samples from the regions without visible symptoms were collected for microscopic analysis. All clones presented chlorosis and necrosis at the fourth day of glyphosate exposure, regardless of the formulation used. The UFVO4 clone did not show any anatomical damage. The other clones suffered plasmolysis, cellular collapse, hypertrophy and formation of cicatrisation tissue. However, changes in leaf blade thickness were not observed. Plants exposed to Roundup transorb ${ }^{\circledR}$ presented the greatest visible intoxication percentage. Anatomically, plants exposed to Roundup $N A^{\circledR}$ showed a higher number of damages. Analysis considering both anatomic and visible damages showed that UFVO6 clone was the most susceptible to the formulations tested. The results confirmed the diagnostic and prognostic value of visual and anatomical analysis, respectively, and showed that these parameters are essential to evaluate clone susceptibility and the the phytotoxic potential of herbicides.
\end{abstract}

Keywords: plant anatomy, herbicide, symptomatology.

Recebido para publicação em 23.8.2007 e na forma revisada em 27.2.2008.

Pós-doutorando do Departamento de Fitotecnia (1tuffi@yahoo.com.br), bolsista do CNPq; ${ }^{3}$ Doutorando em Botânica; ${ }^{4}$ Professora Adjunta do Departamento de Biologia Vegetal; ${ }^{5}$ Mestrando em Fitotecnia; ${ }^{6}$ Professor Titular do Dep. de Fitotecnia; ${ }^{7}$ Estudante de Agronomia. Universidade Federal de Viçosa, Dep. de Fitotecnia, Av. P. H. Rolfs, s/n, CEP 36570-000 Viçosa, MG. 


\section{INTRODUÇÃO}

A garantia de sustentabilidade e competitividade no setor florestal depende, entre outros fatores, de uma base florestal que atenda a padrões cada vez mais exigentes em termos de qualidade, produtividade e responsabilidade social e ambiental (Brito, 1995). Entre os fatores responsáveis pelos ganhos de produtividade está o uso de diferentes métodos de controle das plantas daninhas, isolados ou combinados, visando eficiência, baixo impacto ambiental e diminuição dos custos de produção.

O setor florestal vem procurando aperfeiçoar as práticas de aplicação de herbicidas, como forma de reduzir despesas e diminuir os impactos negativos advindos do contato indesejado de produtos não-seletivos para o eucalipto. Na escolha do herbicida ou da formulação a ser usada devem-se avaliar os riscos e beneficios do uso do produto, considerando-se a forma de aplicação, a importância econômica e os riscos para culturas e áreas não-alvo. A aplicação ideal de um herbicida pressupõe colocar a quantidade certa de ingrediente ativo no alvo desejado, com a máxima eficiência e da maneira mais econômica possivel (Durigan, 1989).

Em áreas onde o controle químico é adotado, a deriva de herbicidas tem sido relatada com freqüência. Em aplicações dirigidas de produtos não-seletivos, como no caso dos herbicidas à base de glyphosate, a própria cultura pode ser afetada pelo contato com o herbicida, podendo causar intoxicação, queda no crescimento e até a morte das plantas (Tuffi Santos et al., 2007a).

Para o eucalipto, várias formulações à base de glyphosate são registradas. Entretanto, são escassas as informações tanto no que se refere ao efeito da intoxicação dos diversos produtos disponiveis no mercado sobre a cultura quanto aos niveis de tolerância dos diferentes genótipos. Em avaliações do efeito da deriva de glyphosate em plantas, além da porcentagem de intoxicação, alterações no crescimento e desenvolvimento das plantas (Miller et al., 2004; Tuffi Santos et al., 2005, 2007; Yamashita et al., 2006; Vieira et al., 2006) e caracteres microscópicos têm sido utilizados isoladamente (Tuffi Santos et al., 2006) ou em conjunto com a sintomatologia (Tuffi Santos et al., 2005, 2007). Essas abordagens permitem a melhor avaliação das injúrias, além de fornecer informações sobre as mudanças na proporção dos tecidos foliares. Entretanto, a descrição de injúrias microscópicas em folhas aparentemente sadias é pouco documentada.

Diante do exposto, objetivou-se estudar o efeito de quatro formulações de glyphosate sobre a estrutura foliar de seis clones de E. grandis.

\section{MATERIAL E MÉTODOS}

O experimento foi conduzido em ambiente protegido, usando mudas padronizadas de seis clones, hibridos de Eucalyptus grandis, adquiridos na Suzano Papel e Celulose, codificados como UFV01, UFV02, UFV03, UFV04, UFV05 e UFV06. As mudas foram cultivadas em vasos de $10 \mathrm{~L}$ preenchidos com substrato constituído de $5 / 6$ de solo argiloso e $1 / 6$ de areia, adubado com 130 g de $\mathrm{N}-\mathrm{P}_{2} \mathrm{O}_{5}-\mathrm{K}_{2} \mathrm{O}$ (6-30-6) e 5,2 g de calcário na proporção de $\mathrm{Ca}: \mathrm{Mg}=4: 1$ equivalentes. Após o transplantio, realizaram-se adubações quinzenais de cobertura com $1,0 \mathrm{~g}$ por vaso da mistura de minerais Ouro Verde ${ }^{\circledR}(15-$ 15-20 de $\mathrm{N}-\mathrm{P}_{2} \mathrm{O}_{5}-\mathrm{K}_{2} \mathrm{O}+$ pequenas quantidades de $\mathrm{Ca}, \mathrm{S}, \mathrm{Mg}, \mathrm{B}, \mathrm{Zn}$, Mn e Fe), previamente dissolvido em $100 \mathrm{~mL}$ de água.

Utilizou-se o delineamento de blocos casualizados, com quatro repetições, sendo considerado como parcela experimental cada vaso contendo uma planta. A dose aplicada correspondeu a 129,6 $\mathrm{g} \mathrm{ha}^{-1}$ de glyphosate (9\% da dose de $1.440 \mathrm{~g} \mathrm{ha}^{-1}$ desse herbicida), das seguintes formulações comerciais: Roundup transorb $^{\circledR}$, Scout ${ }^{\circledR}$, Roundup NA ${ }^{\circledR}$ e Zapp QI ${ }^{\circledR}$. O ensaio foi instalado em arranjo fatorial de $6 \times 4+6$, sendo seis clones e quatro formulações + seis testemunhas sem herbicida (uma para cada clone).

A aplicação foi realizada sobre as plantas de eucalipto, que estavam com 0,5 m de altura em média, utilizando pulverizador costal com pressão constante mantida a $\mathrm{CO}_{2}$ pressurizado, munido de barra com dois bicos leque TT110.02, operando a $250 \mathrm{KPa}$ de pressão, e volume de calda de aproximadamente 150 L. A pulverização foi direcionada sobre o eucalipto, simulando deriva, de modo a não atingir o terço superior das plantas.

Diariamente, após aplicação do herbicida, foram avaliadas à vista desarmada as alterações 
morfológicas nos órgãos aéreos. Aos 14 dias após a aplicação (DAA), realizou-se a avaliação visual da porcentagem de intoxicação causada pelo glyphosate, de acordo com a presença de injúrias. Foram considerados o número e o tamanho proporcional das lesões referentes à intoxicação pelo herbicida em relação à área foliar da planta, utilizando a seguinte escala: levemente injuriada (com sintomas ocupando $25 \%$ da área foliar), moderadamente injuriada (com sintomas ocupando de 25 a 50\% da área foliar), muito injuriada (com sintomas ocupando de 50 a $75 \%$ da área foliar) e extremamente injuriada (com sintomas em mais de $75 \%$ da área foliar). Os sintomas foram descritos e documentados fotograficamente.

Os efeitos provocados pelas formulações de glyphosate foram anatomicamente caracterizados em folhas coletadas no terceiro nó do primeiro ramo basal das plantas de eucalipto aos 14 DAA, procedendo-se a quatro repetições. Amostras da porção mediana de uma folha de cada planta foram fixadas em $\mathrm{FAA}_{50}$ e estocadas em etanol 70\% (Johansen, 1940). Realizouse a desidratação do material em série etílica, seguida pela inclusão em metacrilato. Cortes transversais, com $8 \mu \mathrm{m}$ de espessura, foram obtidos com o auxílio de um micrótomo rotativo de avanço automático (RM2155, Leica Microsystems Inc., Deerfield, USA), corados com azul de toluidina pH 4,0 (O’Brien \& McCully, 1981) e, posteriormente, dispostos em lâminas com Permount. As análises e a documentação fotográfica foram feitas utilizando-se um microscópio fotônico (AX7OTRF, Olympus Optical, Tokyo, Japão) com sistema U-Photo.

As mudanças estruturais causadas pelo herbicida foram avaliadas pela análise ao microscópio de luz de todos os cortes obtidos, e os danos anatômicos (DA) descritos, quantificados (registrando a presença ou ausência numa planilha) e documentados fotograficamente. Posteriormente, elaborou-se uma escala de acordo com a média da presença dos quatro principais DA observados, sendo: 0 - ausência de injúrias (sem DA); 1- levemente injuriada (presença de pelo menos 1 DA), 2 - moderadamente injuriada (presença de 2 DA), 3 - muito injuriada (presença de 3 DA) e 4 - extremamente injuriada (presença de 4 DA).

Para análise micromorfométrica, foram mensuradas as espessuras do limbo, do parên- quima paliçádico (Pp), do parênquima lacunoso (P1), da epiderme da face adaxial (Ed) e abaxial (Eb) da folha. Os dados de espessura foram obtidos com auxílio do software Image-Pro Plus versão 4.1 para Windows ${ }^{\circledR}$ (Media Cybernetics, Silver Spring, MD, USA), perfazendo um total de 27 observações/repetição para cada estrutura avaliada.

Os dados micromorfométricos foram submetidos à análise de variância pelo teste $\mathrm{F}$, e as médias, comparadas pelo teste de Tukey a $5 \%$ de probabilidade.

\section{RESULTADOS E DISCUSSÃO}

Nas plantas expostas às diferentes formulações de glyphosate, todos os clones apresentaram cloroses (Figura 1B) e necroses a partir do quarto dia de exposição tanto na porção basal (proximal ao pecíolo) quanto apical das folhas (Figura 1C, D). Tuffi Santos et al. (2005) relataram sintomas foliares semelhantes em plantas de Eucalyptus urograndis, pulverizadas com 172,8 e 345,6 $\mathrm{g} \mathrm{ha}^{-1}$ de glyphosate. Entre as formulações testadas, somente o Roundup transorb ${ }^{\circledR}$ ocasionou danos visuais superiores a $25 \%$ da área foliar total em todos os clones avaliados, enquanto os clones expostos ao Zapp QI ${ }^{\circledR}$ apresentaram a menor intoxicação (Tabela 1). Entre os clones, UFV06 e UFV05 obtiveram, respectivamente, a maior e a menor intoxicação (Tabela 1).

As cloroses observadas podem ser reflexos da degeneração dos cloroplastos e/ou inibição da formação da clorofila - efeito semelhante ao relatado para outras espécies de plantas expostas ao glyphosate (Campbell et al., 1976; Cole et al., 1983).

Os seis clones de Eucalyptus grandis estudados apresentam folhas anfiestomáticas, e na face adaxial da epiderme os estômatos ficam restritos às proximidades da nervura mediana (Figura 2A). As folhas são glabras e possuem epiderme unisseriada, mesofilo dorsiventral formado por parênquima lacunoso proeminente e uma a duas camadas de parênquima paliçádico (Figura 2B). Cavidades secretoras encontram-se dispersas no mesofilo sob a epiderme (Figura 2C, D, E). A nervura mediana possui feixes vasculares bicolaterais e o parênquima paliçádico é interrompido por uma calota de colênquima (Figura $2 \mathrm{~A}, \mathrm{D}, \mathrm{E})$. A 
estrutura anatômica observada nos seis clones de E. grandis é semelhante e está de acordo tanto com o descrito para a espécie na literatura (Tuffi Santos et al., 2005) quanto para o gênero (Metcalfe \& Chalk, 1979).

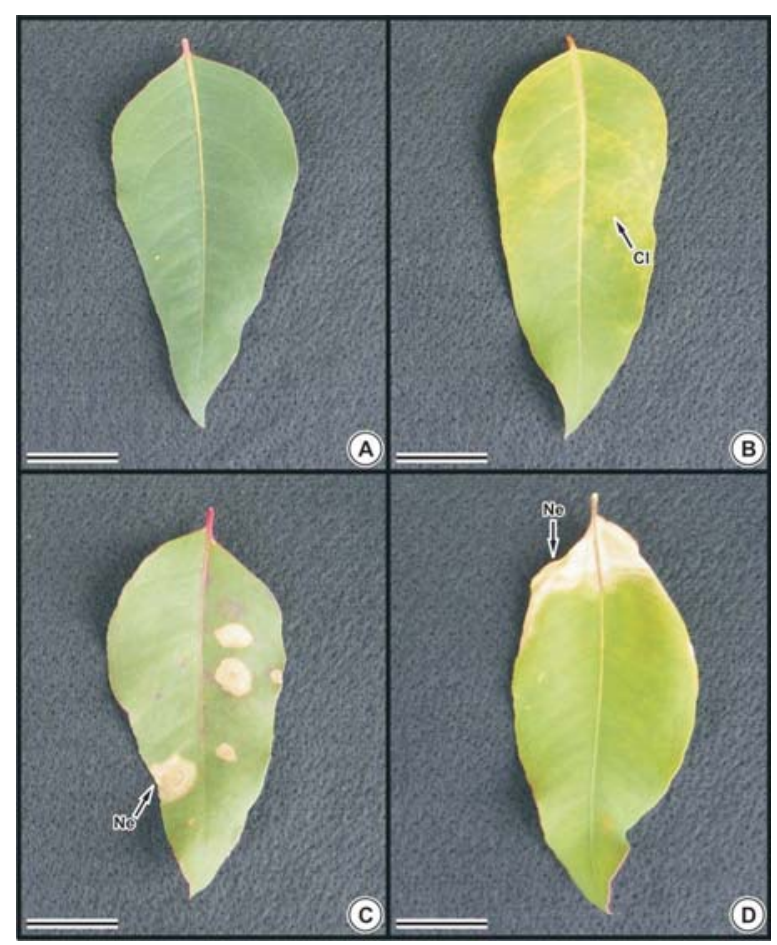

Figura 1 - Sintomas foliares em folhas de E. grandis (clone UFV06) expostas à deriva de diferentes formulações de glyphosate (129.6 $\mathrm{g} \mathrm{ha}^{-1}$ ), 14 dias após a aplicação. A. Tratamento controle. B. Cloroses $(\mathrm{Cl})$. C. Necroses marginais e intervenais $(\mathrm{Ne})$. D. Necrose na base da folha. Barras = $25 \mathrm{~mm}$.

Tabela 1 - Intoxicação observada nas folhas de clones de E. grandis expostos à deriva simulada de diferentes formulações de glyphosate, avaliada aos 14 dias

\begin{tabular}{|c|c|c|c|c|c|}
\hline \multirow[b]{2}{*}{ Clone } & \multicolumn{4}{|c|}{ Formulação } & \multirow[b]{2}{*}{ Média } \\
\hline & $\begin{array}{l}\text { Roundup } \\
\mathrm{NA}^{\circledR}\end{array}$ & Scout $^{\mathbb{B}}$ & $\begin{array}{l}\text { Roundup } \\
\text { transorb }^{\circledR}\end{array}$ & $\begin{array}{l}\text { Zapp } \\
\mathrm{QI}^{\mathbb{B}}\end{array}$ & \\
\hline UFV01 & 1 & 2 & 2 & 2 & 1,75 \\
\hline UFV02 & 2 & 2 & 2 & 1 & 1,75 \\
\hline UFV03 & 2 & 1 & 2 & 1 & 1,50 \\
\hline UFV04 & 2 & 2 & 2 & 1 & 1,75 \\
\hline UFV05 & 1 & 1 & 2 & 1 & 1,25 \\
\hline UFV06 & 2 & 2 & 2 & 2 & 2,00 \\
\hline Média & 1,67 & 1,67 & 2,00 & 1,33 & \\
\hline
\end{tabular}

Legenda: 1 (levemente injuriada, até 25\%); 2 (moderadamente injuriada, 25 a $50 \%$ da área injuriada); 3 (muito injuriada, de 50 a $75 \%$ ); 4 (extremamente injuriada, mais de $75 \%$ ).

Planta Daninha, Viçosa-MG, v. 26, n. 1, p. 9-16, 2008
Apesar de visualmente sadias, as amostras coletadas para os estudos anatômicos apresentaram alterações estruturais na nervura mediana (Figura 3) e na região intermediária da folha (Figura 4). Na região da nervura mediana, os danos ocorrem em ambas as faces da folha (Figura 3A, B). O parênquima lacunoso adjacente à região dos estômatos aparece colapsado sem a ruptura da epiderme (Figura 3B). O glyphosate ocasionou o rompimento da parede periclinal externa da epiderme e, consecutivamente, o colapso de tecidos mais internos, como o colênquima subepidérmico, no qual se verifica a formação do tecido de cicatrização (Figura 3A), também observado no mesofilo (Figura 3B). Ocorreu a plasmólise de quase todos os tecidos (Figura 3C), porém o xilema permaneceu intacto (Figura 3D).

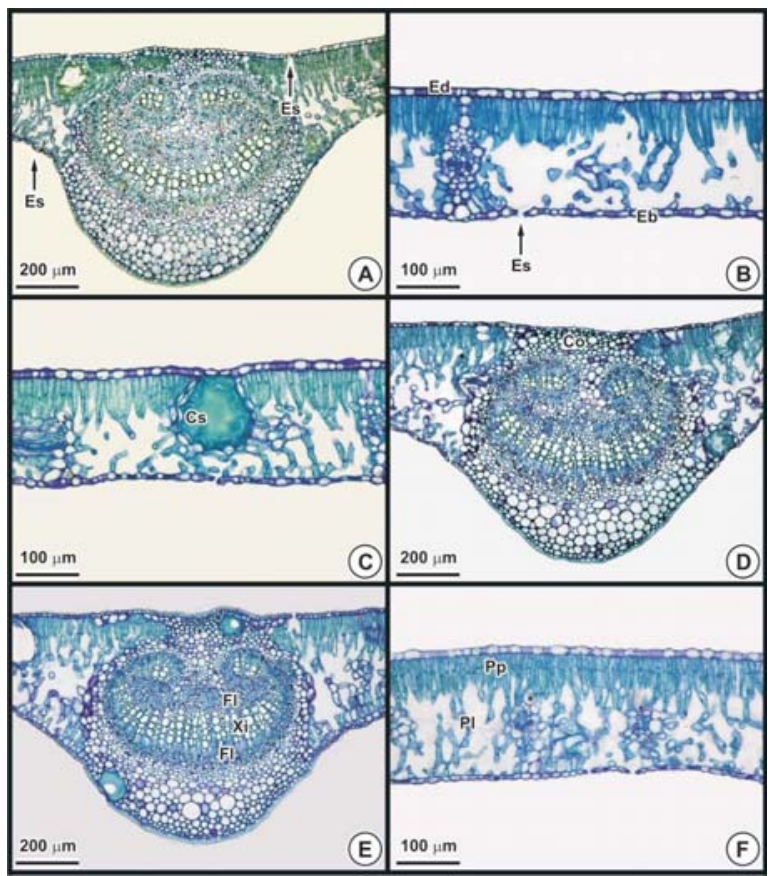

Figura 2 - Anatomia foliar de seis clones de E. grandis não submetidos à deriva de glyphosate (secções transversais ao microscópio de luz). A, D e E. Nervura mediana. B, C e F. Região entre nervura e margem. A. Clone UFV01: estômatos (Es) em ambas as faces da folha. B. Clone UFV02: face adaxial (Ed) e abaxial (Eb) da epiderme unisseriada. C. Clone UFV03: cavidades secretoras no mesofilo (Cs). D. Clone UFV04: parênquima paliçádico $(\mathrm{Pp})$ interrompido por calota de colênquima $(\mathrm{Co})$. E. Clone UFV05: feixe bicolateral. F. Clone UFV06: mesofilo dorsiventral. Abreviaturas: Fl (floema), Pl (parênquima lacunoso) e Xi (xilema). 


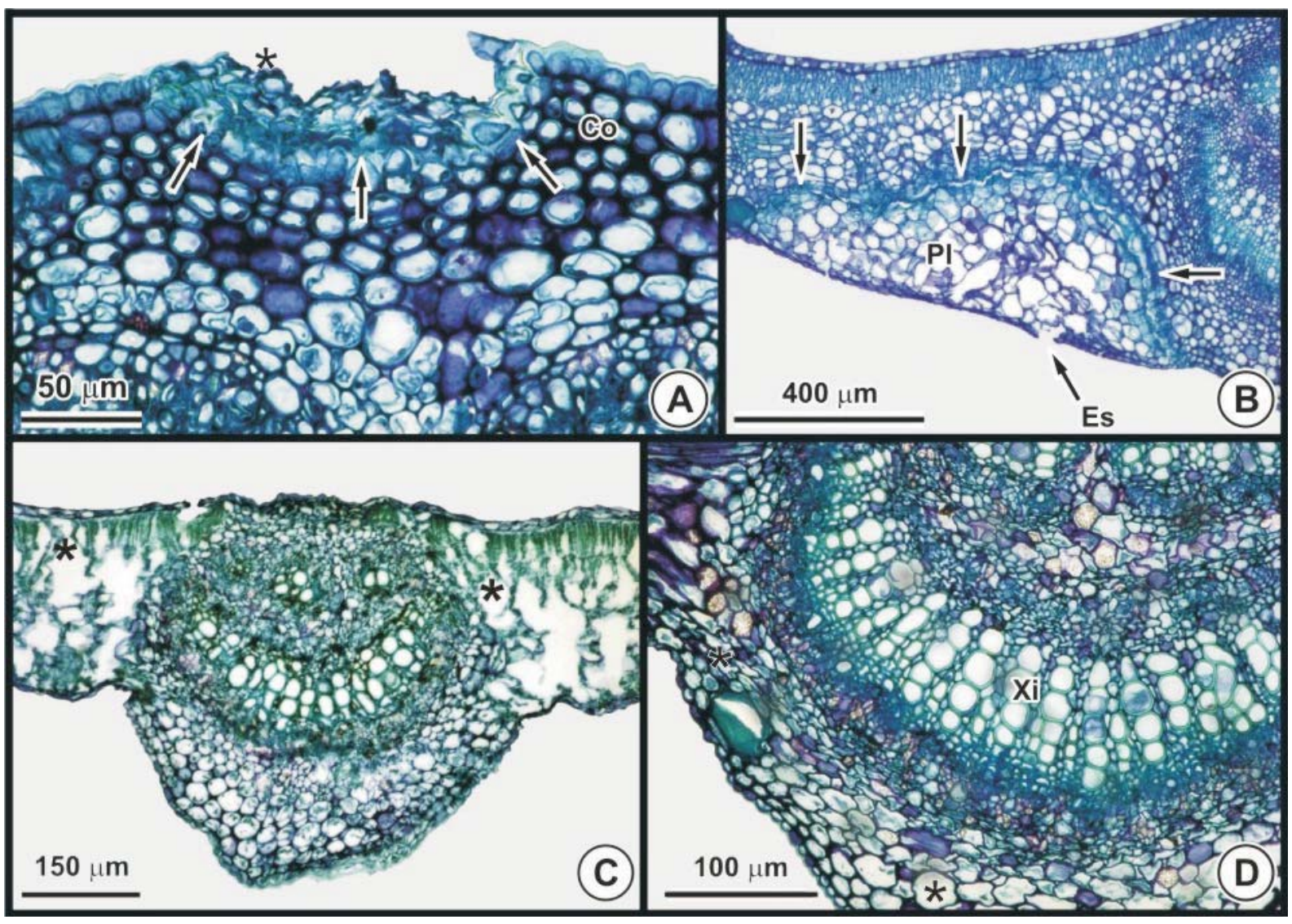

Figura 3 - Alterações estruturais na nervura mediana da folha de clones de E. grandis submetidos ao glyphosate (secções transversais ao microscópio de luz). A. Clone UFV05: início de necrose a partir da face adaxial da folha $(*)$ e formação de tecido de cicatrização (setas) na região do colênquima (Co). B. Clone UFV02: colapso do parênquima lacunoso (Pl) e formação de tecido de cicatrização (setas) adjacente. C. Clone UFV01: plasmólise do mesofilo e formação de espaços intercelulares no parênquima paliçádico $(*)$. D. Clone UFV06: xilema intacto (Xi) e células parenquimáticas colapsadas $\left({ }^{*}\right)$. Abreviatura: Es (estômato)

Na região intermediária da folha, as injúrias iniciam-se tanto a partir do mesofilo (Figura 4A, B) quanto da epiderme (Figura 4C, D). Os danos são caracterizados por plasmólise (Figura 4A), hipertrofia (Figura 4B), acúmulo de compostos intensamente corados pelo azul de toluidina (Figura 4B, C, D, F), colapso celular (Figura 4C, D), hiperplasia (Figura 4E) e a formação de tecido de cicatrização (Figura 4C, $\mathrm{D}, \mathrm{E}, \mathrm{F}$ ), que isola parcial (Figura $4 \mathrm{C}, \mathrm{D}, \mathrm{E}$ ) ou totalmente (Figura 4F) a área afetada da sadia.

Os compostos com coloração intensa em células danificadas dos clones de eucalipto avaliados assemelham-se aos compostos fenólicos observados por Tuffi Santos et al. (2005) em clones expostos ao glyphosate; entretanto, testes histoquímicos devem ser realizados para confirmação da natureza desses conteúdos.
Estudos demonstram que estresses bióticos e abióticos podem induzir acréscimos no conteúdo de fenóis em plantas (Sant'Anna-Santos et al., 2006a, b, 2007; Sant'Anna-Santos \& Azevedo, 2007). No entanto, a rota do chiquimato é a principal via de formação de compostos fenólicos, sendo esta inibida pela ação direta do glyphosate quando da exposição das plantas a esse herbicida.

A diferenciação de um tecido de cicatrização em clones de eucalipto submetidos ao glyphosate funciona como uma barreira que previne o progresso da necrose para outras regiões da folha. A formação do tecido de cicatrização é resultante da habilidade das plantas de formar novos tecidos a partir da capacidade proliferativa de células parenquimáticas (Dickison, 2000), também sendo observado em 


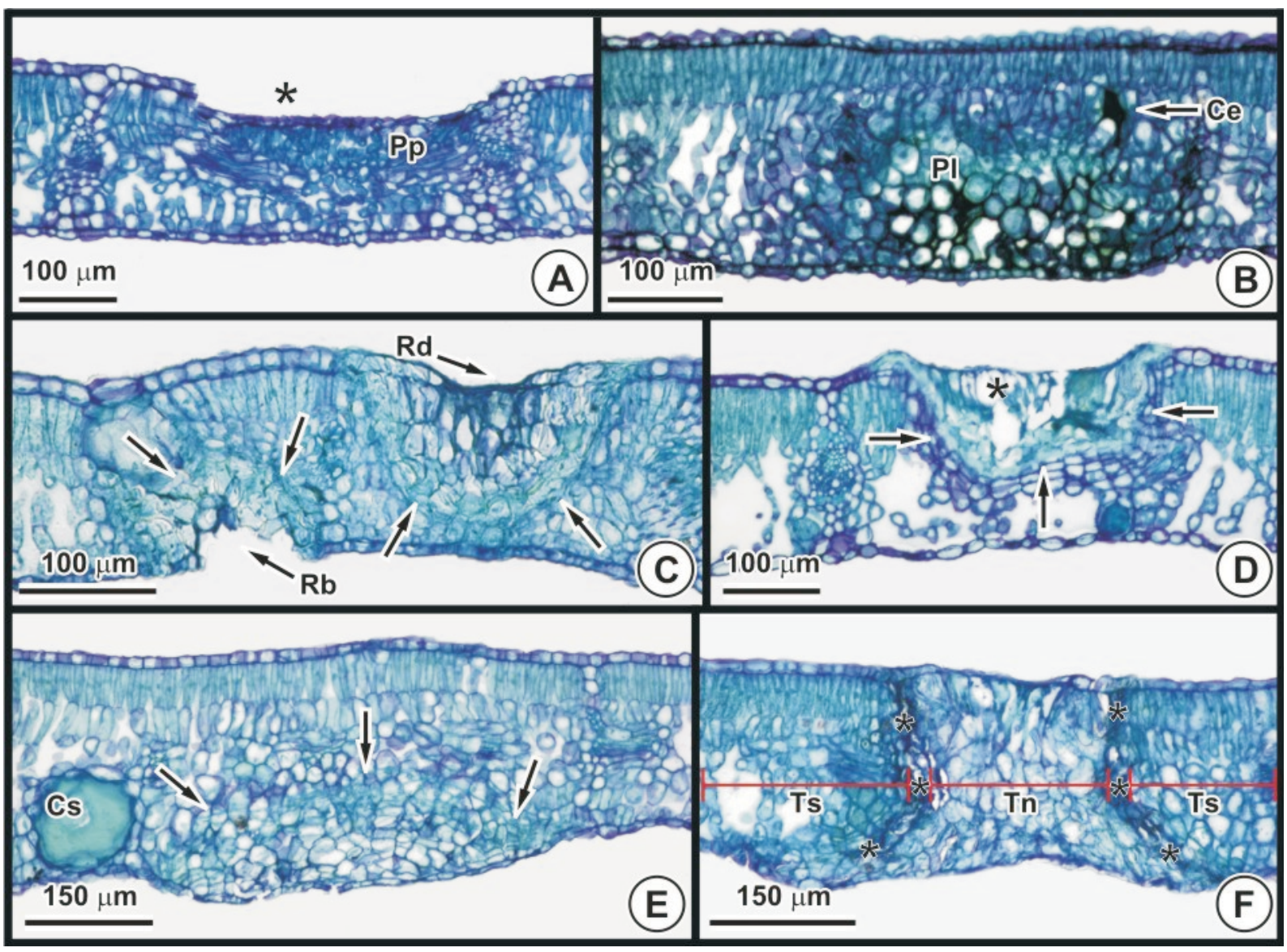

Figura 4 - Alterações estruturais na região entre a margem e a nervura mediana de folhas de clones de E. grandis submetidos ao glyphosate (secções transversais ao microscópio de luz). A. Clone UFV02: plasmólise do parênquima paliçádico (Pp) e retração da face adaxial da folha $(*)$. B. Clone UFV06: hipertrofia do parênquima lacunoso ( $\mathrm{Pl}$ ) e acúmulo de compostos escuros (Ce) no parênquima paliçádico. C. Clone UFV03: ruptura da face adaxial (Rd) e abaxial (Rb) da folha e formação de tecido de cicatrização (setas). D. Clone UFV01: colapso da face adaxial da folha e do parênquima paliçádico com formação de tecido de cicatrização (setas) adjacente à área necrosada $(*)$. E. Clone UFV05: tecido de cicatrização $(*)$ isolando a face abaxial da folha (setas). F. Clone UFV05: tecido de cicatrização isolando o tecido sadio (Ts) do necrosado (Tn).

resposta ao estresse causado por poluentes atmosféricas (Silva et al., 2005; Sant'AnnaSantos et al., 2006b).

Nenhuma formulação ocasionou danos microscópicos em todos os clones testados; no clone UFV04 não foram observadas injúrias (Tabela 2). Dos clones testados, o UFV06 apresentou a maior quantidade de danos anatômicos (Tabela 2).

Analisando os dados de intoxicação e os danos anatômicos, podem-se classificar os clones UFV06 e UFV05, respectivamente, como o mais sensível e o mais tolerante à ação do glyphosate. Para as formulações testadas, considerando-se os dados de intoxicação, o
Roundup transorb ${ }^{\circledR}$ foi o mais prejudicial ao eucalipto (Tabela 1), enquanto para os danos anatômicos o Roundup $\mathrm{NA}^{\circledR}$ causou o maior número de injúrias (Tabela 2). Quanto à intoxicação das plantas, o Zapp $\mathrm{QI}^{\circledR}$ foi a formulação menos fitotóxica.

$\mathrm{Na}$ análise micromorfométrica, o efeito isolado para formulação e para interação formulação $x$ clone foi não-significativo $(\mathrm{P}>0,05)$ para todas as espessuras de tecido e do limbo foliar. Já entre clones houve diferença $(P<0,05)$ para espessura do limbo, do parênquima paliçádico $(\mathrm{Pp})$, do parênquima lacunoso $(\mathrm{Pl})$ e da epiderme das faces adaxial (Ed) e abaxial (Eb) da folha. Os valores médios da espessura do limbo foliar, 
Tabela 2 - Danos anatômicos (DA) observados nas folhas de clones de E. grandis expostos a diferentes formulações de glyphosate, avaliados aos 14 dias

\begin{tabular}{|c|c|c|c|c|c|}
\hline \multirow[b]{2}{*}{ Clone } & \multicolumn{4}{|c|}{ Formulação } & \multirow[b]{2}{*}{ Média } \\
\hline & $\begin{array}{c}\text { Roundup } \\
\mathrm{NA}^{\otimes}\end{array}$ & Scout $^{\circledR}$ & $\begin{array}{l}\text { Roundup } \\
\text { transorb }^{\mathbb{B}}\end{array}$ & $\begin{array}{c}\text { Zapp } \\
\mathrm{QI}^{\mathbb{R}}\end{array}$ & \\
\hline UFV01 & 2 & 2 & 1 & 1 & 1,50 \\
\hline UFV02 & 1 & 1 & 2 & 1 & 1,25 \\
\hline UFV03 & 1 & 2 & 0 & 1 & 1,00 \\
\hline UFV04 & 0 & 0 & 0 & 0 & 0,00 \\
\hline UFV05 & 3 & 0 & 0 & 0 & 0,75 \\
\hline$\overline{\text { UFV06 }}$ & 3 & 2 & 1 & 2 & 2,00 \\
\hline Média & 1,67 & 1,17 & 0,67 & 0,83 & \\
\hline
\end{tabular}

Legenda: 0 (ausência de DA); 1 (levemente injuriada, presença de 1 DA); 2 (moderadamente injuriada, presença de $2 \mathrm{DA}$ ); 3 (muito injuriada, presença de $3 \mathrm{DA}$ ); 4 (extremamente injuriada, presença de 4 DA).

do $\mathrm{Pp}$, do Pl, da Ed e Eb encontram-se nas Tabelas 4 e 5, podendo ser usados em estudos de descrição da espécie E. grandis. O clone UFV05 apresentou a maior espessura do limbo foliar, do Pl, da Ed e da Eb. Por sua vez, o clone UFVO1 mostrou os menores valores para espessura do limbo, Pp, Ed e Eb (Tabela 3). A espessura do $\mathrm{Pp}$, importante característica ligada à proteção foliar contra alta intensidade luminosa, apresentou, respectivamente, o maior e o menor valor nos clones UFV04 e UFVO1 (Tabela 3). As diferenças de espessura dos tecidos e do limbo foliar são discretas, não podendo ser distinguidas sem o auxílio de medições (Tabela 3).

A espessura do limbo e dos tecidos analisados dos seis clones não mostrou mudanças em função da aplicação ou não de glyphosate nas formulações testadas (Tabela 4).

A avaliação microscópica realizada no presente trabalho ressalta a importância dessa ferramenta na identificação da tolerância diferencial entre genótipos de eucalipto ao glyphosate, corroborando outros resultados encontrados na literatura, especialmente quanto à micromorfologia (Tuffi Santos et al., 2007a) e à anatomia foliar (Tuffi Santos et al., 2005, 2006), ou mesmo no diagnóstico precoce das alterações morfológicas em resposta a herbicidas (Tuffi Santos et al., 2005).

A avaliação anatômica da estrutura foliar foi eficaz na descrição de injúrias invisiveis à vista desarmada e ofereceu subsídios para discriminação dos clones quanto à tolerância
Tabela 3 - Espessura do limbo e dos tecidos foliares de clones de E. grandis submetidos à deriva de glyphosate. $\mathrm{Pp}=$ parênquima paliçádico; $\mathrm{Pl}$ = parênquima lacunoso; $\mathrm{Ed}=$ face adaxial da epiderme; $\mathrm{Eb}$ = face abaxial da epiderme

\begin{tabular}{|c|c|c|c|c|c|}
\hline \multirow{2}{*}{ Clone } & \multicolumn{5}{|c|}{ Espessura $(\mu \mathrm{m})$} \\
\cline { 2 - 6 } & Limbo & Pp & Pl & Ed & Eb \\
\hline UFV01 & $182,73 \mathrm{~b}$ & $55,06 \mathrm{~b}$ & $104,33 \mathrm{ab}$ & $11,12 \mathrm{~b}$ & $8,82 \mathrm{c}$ \\
\hline UFV02 & $198,21 \mathrm{~b}$ & $61,56 \mathrm{ab}$ & $113,93 \mathrm{ab}$ & $11,55 \mathrm{~b}$ & $8,88 \mathrm{c}$ \\
\hline UFV03 & $182,88 \mathrm{~b}$ & $59,88 \mathrm{~b}$ & $99,01 \mathrm{~b}$ & $13,17 \mathrm{ab}$ & $9,48 \mathrm{bc}$ \\
\hline UFV04 & $190,00 \mathrm{~b}$ & $66,28 \mathrm{a}$ & $101,20 \mathrm{ab}$ & $12,94 \mathrm{ab}$ & $11,04 \mathrm{ab}$ \\
\hline UFV05 & $205,47 \mathrm{a}$ & $59,48 \mathrm{~b}$ & $121,28 \mathrm{a}$ & $14,69 \mathrm{a}$ & $12,19 \mathrm{a}$ \\
\hline UFV06 & $192,35 \mathrm{~b}$ & $59,39 \mathrm{~b}$ & $111,00 \mathrm{ab}$ & $12,11 \mathrm{~b}$ & $9,46 \mathrm{bc}$ \\
\hline Média & 191,94 & 60,28 & 108,46 & 12,60 & 9,98 \\
\hline CV (\%) & 8,67 & 12,45 & 10,91 & 9,53 & 9,17 \\
\hline
\end{tabular}

Médias seguidas pela mesma letra na coluna não diferem entre si pelo teste de Tukey a $5 \%$ de probabilidade.

Tabela 4 - Espessura do limbo e dos tecidos foliares de clones de $E$. grandis submetidos à deriva de glyphosate em função das formulações testadas. $\mathrm{Pp}=$ parênquima paliçádico; $\mathrm{Pl}=$ parênquima lacunoso; $\mathrm{Ed}$ = face adaxial da epiderme; $\mathrm{Eb}=$ face abaxial da epiderme

\begin{tabular}{|c|c|c|c|c|c|}
\hline \multirow{2}{*}{ Formulação } & \multicolumn{5}{|c|}{ Espessura $(\mu \mathrm{m})$} \\
\hline & Limpo $^{\text {ns }}$ & $\mathrm{Pp}^{\mathrm{ns}}$ & $\mathrm{Pl}^{\mathrm{ns}}$ & $\mathrm{Ed}^{\mathrm{ns}}$ & $\mathrm{Eb}^{\mathrm{ns}}$ \\
\hline Roundup NA $\mathrm{A}^{(1)}$ & 188,33 & 60,12 & 103,07 & 13,01 & 10,32 \\
\hline Scout $^{(\mathbb{B}}$ & 184,57 & 57,36 & 104,50 & 11,82 & 9,55 \\
\hline Roundup transorb $^{\circledR}$ & 189,99 & 59,58 & 105,32 & 13,03 & 10,11 \\
\hline Zapp QI ${ }^{\mathbb{B}}$ & 193,51 & 61,39 & 110,63 & 12,52 & 9,96 \\
\hline Testemunha & 203,30 & 62,93 & 118,78 & 12,60 & 9,95 \\
\hline $\mathrm{CV}(\%)$ & 15,16 & 11,23 & 39,25 & 12,23 & 22,71 \\
\hline
\end{tabular}

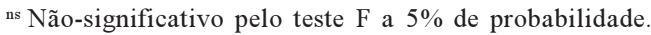

às diferentes formulações de glyphosate. O clone UFV06, tanto na análise anatômica quanto na visual, foi o mais sensivel à ação das formulações testadas. Os danos anatômicos observados no presente trabalho (plasmólise, hipertrofia e hiperplasia celular, formação de tecido de cicatrização e acúmulo de compostos intensamente corados) são semelhantes aos descritos por Tuffi Santos et al. (no prelo), que caracterizaram, anatomicamente, os danos visuais causados pelo glyphosate em clones de E. urograndis, E. grandis e no híbrido $E$. urograndis $\mathrm{x} E$. grandis, comprovando que a alteração estrutural antecede o surgimento do sintoma.

Em associação, os dados de sintomatologia e anatomia permitiram indicar o Zapp $\mathrm{QI}^{\circledR}$ como a formulação de menor risco para a cultura do eucalipto quanto aos efeitos indesejáveis do contato do glyphosate com a cultura. Essa 
informação deve ser considerada na escolha da formulação a ser utilizada no manejo de plantas daninhas nesta cultura, porém levando-se em consideração a eficiência no controle, as condições ambientais e o preço do produto no mercado. Nos casos em que o objetivo é controlar as plantas de eucalipto, como na dessecação da rebrota para o plantio de novas mudas, o Roundup transorb ${ }^{\circledR}$ constitui-se numa boa opção, dado o seu maior efeito tóxico nas plantas, em detrimento das demais formulações testadas. Adicionalmente, essa formulação apresenta absorção mais rápida pela folha de plantas tratadas, o que possibilita maior segurança no sucesso do controle quando da ocorrência de chuvas nas primeiras horas após a aplicação (Santos et al., 2007).

\section{AGRADECIMENTOS}

À Suzano Papel e Celulose e ao CNPq, pelo suporte financeiro.

\section{LITERATURA CITADA}

BRITO, M. A. R. Manejo de plantas daninhas em área de reflorestamento. In: CONGRESSO BRASILEIRO DA CIÊNCIA DAS PLANTAS DANINHAS, 20., 1995, Florianópolis. Resumos... Florianópolis: 1995. p. 92-95.

CAMPBELL, W. F.; EVANS, J. O.; REED, F. C. Effect of glyphosate on chloroplast ultrastructure of quack grass mesophyll cell. Weed Sci., v. 24, p. 22-25, 1976.

COLE, D. J.; CASELEY, J. C.; DODGE, A. D. Influence of glyphosate on selected plant process. Weed Res., v. 23, n. 3, p. $173-183,1983$

DICKISON, W. C. Integrative plant anatomy.

Massachusetts: Harcourt/Academic Press, 2000. 530 p.

DURIGAN, J. C. Comportamento de herbicidas no ambiente. In: SEMINÁRIO TÉCNICO SOBRE PLANTAS DANINHAS E O USO DE HERBICIDAS EM

REFLORESTAMENTO, 1989, Rio de Janeiro. Anais... Rio de Janeiro: SBS/ABRACAV/SIF, 1989. Paginação Irregular

JOHANSEN, D. A. Plant microtechinique. New York: McGraw-Hill Book, 1940. 523 p.

KRUZE, N. D.; TREZZI, M. M.; VIDAL, R. A. Herbicidas inibidores da EPSPS: Revisão de literatura. R. Bras. Herb., v. 1, n. 2, p. 139-146, 2000.

METCALFE, C. R.; CHALK, L. Anatomy of the dicotyledons. New York: Oxford University Press, 1979. v. $1.276 \mathrm{p}$.
MILLER, D. K. et al. Response of non glyphosate resistant cotton to reduced rates of glyphosate. Weed Sci., v. 52, p. 178-182, 2004.

O`BRIEN, T. P.; McCULLY, M. E. The study of plant structure principles and select methods. Melbourne: Termarcarphi Pty, 1981. 45 p.

SANTOS, J. B. et al. Avaliação de formulações de glyphosate sobre soja Roundup Ready. Planta Daninha, v. 25 , n. 1 , p. $165-171,2007$.

SANT'ANNA-SANTOS, B. F. et al. Effects of simulated acid rain on the foliar micromorphology and anatomy of tree tropical species. Environ. Exp. Bot., v. 58, p. 158-168, $2006 \mathrm{a}$

SANT'ANNA-SANTOS, B. F. et al. Effects of simulated acid rain on leaf anatomy and micromorphology of Genipa americana L. (Rubiaceae). Braz. Arch. Biol. Technol., v. 49 , n. 2 , p. $313-321,2006$ b.

SANT’ANNA-SANTOS, B. F. et al. Utilização de parâmetros morfoanatômicos na análise da fitotoxidez do flúor em folhas de Magnolia ovata (A. St. -Hil) Spreng. (Magnoliaceae). R. Árvore, v.31, n. 4, p.761-771, 2007.

SANT'ANNA-SANTOS, B. F.; AZEVEDO, A. A. Aspectos morfoanatômicos da fitotoxidez do flúor em duas espécies arbóreas tropicais. R. Bras. Bioci., v. 5, n.1 , p. 48-50, 2007.

SILVA, L. C. et al. Micromorphological and anatomical alterations caused by simulated acid rain in restinga plants: Eugenia uniflora and Clusia hilariana. Water, Air, Soil Pollut., v. 168, n. 1-4, p.129-143, 2005.

TUFFI SANTOS, L. D. et al. Crescimento e morfoanatomia foliar de eucalipto sob efeito de deriva do glyphosate. Planta Daninha, v. 23, n. 1, p. 133-142, 2005.

TUFFI SANTOS, L. D. et al. Características da epiderme foliar de eucalipto e seu envolvimento com a tolerância ao glyphosate. Planta Daninha, v. 24, n. 3, p. 513-520, 2006.

TUFFI SANTOS, L. D. et al. Morphological responses of different eucalypt clones submitted to glyphosate drift. Environ. Exp. Bot., v. 59, p.11-20, 2007.

TUFFI SANTOS, L. D. et al. Leaf anatomy and morphometry in three eucalypt clones treated with glyphosate. Braz. J. Biol. (in press).

VIEIRA, R. G. et al. Fitointoxicação por herbicidas em áreas de reflorestamento de teca. In: CONGRESSO BRASILEIRO DA CIÊNCIA DAS PLANTAS DANINHAS, 25., 2006, Brasília, Resumos... Brasília: Sociedade Brasileira da Ciência das Plantas Daninhas, 2006. p. 450.

YAMASHITA, O. M. et al. Resposta de varjão (Parkia multijuga) a subdoses de glyphosate. Planta Daninha, v. 24, n. 3 , p. $527-531,2006$ 